\title{
Phytopathogenic Pseudomonas Growth Inhibition by Tartaric Acid New Derivatives
}

\author{
Bella G. Babayan ${ }^{1,2^{*}}$, Aram R. Mikaelyan ${ }^{2}$, Nona L. Asatryan ${ }^{2}$, Marina A. Melkumyan ${ }^{1}$, Samvel A. Bagdasaryan ${ }^{1}$, Anna
} M. Grigoryan ${ }^{1,3}$, Allen S. Baghdasaryan ${ }^{1}$, Tigran M. Soghomonyan ${ }^{1}$

\footnotetext{
${ }^{1}$ National Polytechnic University of Armenia (NPUA), Republic of Armenia (RA), 105 Teryan St, Yerevan, Armenia Bld 17 room, 203, Armenia

2"Armbiotechnology" Scientific and Production Center (SPC), National Academy of Sciences (NAS), Republic of Armenia (RA)

${ }^{3}$ Russian-Armenian (Slavonic) University, 123 Hovsep Emin St, Yerevan 0051, Armenia
}

\author{
DOI: $10.36347 / \mathrm{sajb} .2020 . \mathrm{v} 08 \mathrm{i} 05.003$ \\ | Received: 16.05.2020 | Accepted: 23.05.2020 | Published: 30.05.2020 \\ *Corresponding author: Bella G. Babayan \\ Abstract \\ Original Research Article
}

Antimicrobial resistance is one of the most pressing issues of modern epoch, according to WHO's reports of recent decades. In current paper, 6 new synthetic derivatives of natural antimicrobial compound from plant source - L-tartaric acid, were elaborated in National Polytechnic University of Armenia (NPUA). Biological activity and biodegradation potential of benzyl- cyclohexyl- and phenyl- imides and complex mono amino salts of tartaric acid were tested on phytopathogenic Pseudomonas syringae of soil. Due to results, benzyl- and cyclohexyl- complex salts of tartaric acid are more effective then phenyl mono amino salt. As the prospective and a comparably ecologically safe alternative for combating antimicrobial resistance in this plant pathogen $P$. syringae, complex salts are more effective than the appropriate imide derivatives. The obtained compounds are effective against the other opportunistic pathogenic Pseudomonas ( $P$. aeruginosa, $P$. fluorescens, etc.). Besides, they are biodegradable by soil non-pathogenic $P$. chlororaphis group representatives.

Keywords: Tartaric acid imides, tartaric acid complex salts, plasmids, Pseudomonas syringae, Pseudomonas syringae, path. Lachrymans, Pseudomonas syringae, path. Tabaci, multi-drug resistance, phytopathogen, soil bacteria.

Copyright @ 2020: This is an open-access article distributed under the terms of the Creative Commons Attribution license which permits unrestricted use, distribution, and reproduction in any medium for non-commercial use (NonCommercial, or CC-BY-NC) provided the original author and source are credited

\section{INTRODUCTION}

Tartaric acid (TA) is a natural aldaric acids mostly presented in plants [1]. This acid and the salts of it (tartrates) are well-known as antimicrobial active compounds, which are broadly used in chemical and food industry, as safe preservatives and conservation agents [2, 3]. One of the prospective directions of antimicrobial active compound elaboration is the derivatization of natural substances, such as like organic aldaric acid to the appropriate imides and amides $[4,5]$.

Pseudomonas are well-known as Gram-negative bacteria with extremely high level of adaptation properties, including the resistance to various antimicrobial agents, such as like antibiotics. Beside they are capable of degradation of different natural and toxic synthetic xenobiotics. All these properties become a cause of additional complications for the treatment of pseudomonas infections in animal, human and plant organism [6, 7]. P. syringae is the one of common phytopathogenic bacteria, represented world around.
They have wide range of genetic mechanisms for synthesis of specific enzymes and that is why it has high level of antibiotic resistance, as well as high virulence with complex influence on plant immune system. According to World Health Organization (WHO) reports, the problem of drug resistance and the spread of it among the various pathogens today is being extremely important. Thus, multi-drug resistance is being considered as one of the research priorities of WHO for this century. It is driven by the overuse of antimicrobials in people, but also in animals, especially those used for food production, as well as in the environment. WHO is working with these sectors to implement a global action plan to tackle antimicrobial resistance by increasing awareness and knowledge, reducing infection, and encouraging prudent use of antimicrobials [8-10].

In current paper there were researched the antibacterial effects of 6 new synthetic derivatives of tartaric acid: benzylimide, cyclohexylimide, benzyl mono amino salt and cyclohexyl mono amino salt of 
tartaric acid on growth of some phytopathogenic strains of soil Pseudomonas syringae.

\section{METHODS}

The homological range of new semisynthetic derivatives of tartaric acid: 3 imides and 3 complex mono amino salts were obtained by targeted derivatization of natural L-tartaric acid. L-tartaric is ecologically safe and harmless compound, which is cheap, being mainly produced in form of cream of tartar (the wine industry main waste product). For the targeted construction of optically active imides and mono amino salts of tartaric acid there were used some bioinformatical, like docking analysis and chemical technics of systhesis and purification. As a result of them, at the basic research laboratory of New Agrarian Pesticides Creation and the Quality Control at National
Polytechnic University of Armenia (NPUA) was elaborated, a technologically easy realizable two step improved procedure. It is scematically presented on Fig-1. This technic was based on natural L-tartaric acid, which was purified from cream of tartar. The desired compounds were being isolated in good yields: $80-85 \%$. The synthesis processes takes place according to the simple 2 stage technology based on the ecologically safe procedure of L-tartaric acid purification from the cream of tartar and the further derivatization of it $[11,12]$. The structures of imides: benzylimide of tartaric acid, phenylimide of tartaric acid, cyclohexylimide of tartaric acid, as well as complex salts: benzyl mono amino salt of tartaric acid, phenyl mono amino salt of tartaric acid, cyclohexyl monoamino salt of tartaric acid are presented in Fig-2.

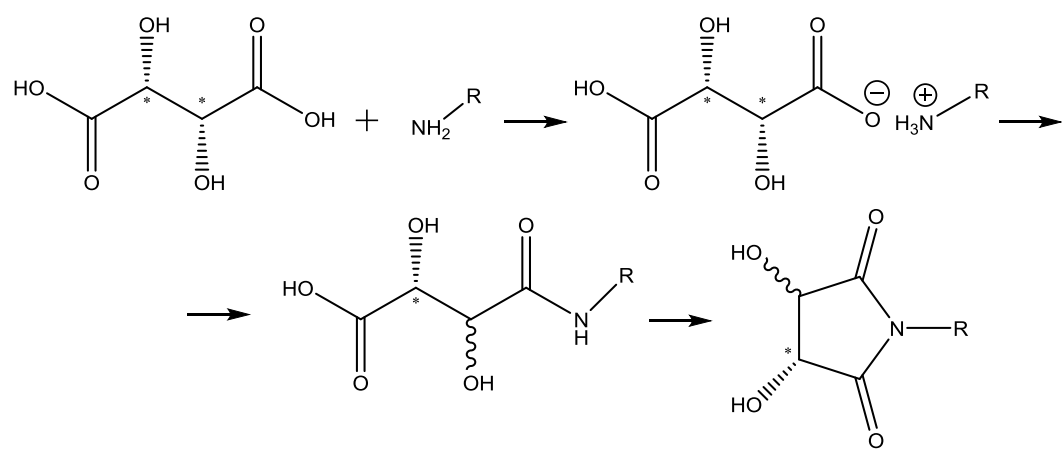

Fig-1: Tartaric acid synthetic derivatives obtaining principal scheme. ( $R$ - Could be benzyl-, cyclohexyl- of phenyl- radical) [11]

For this research there were used the various non-pathogenic and opportunistic pathogenic strains of Pseudomonas and other genera (Pseudomonas syringae, $P$. aeruginosa, E. coli), which were given taken from The National Collection of Microorganisms of Microbe Depository Centre (MDC), "Armbiotechnology" Scientific \& Production Center (SPC), National Academy of Sciences (NAS), Republic of Armenia (RA). All the tested strains of bacteria were cultivated on different liquid and solid nutrient agarised and appropriate selective cultural media with antibiotics of different classes and generations, mainly used in medicine, veterinary and agriculture practice, according to standard protocols.

The selective media, which were used for the studying microbe cultivation and antibiotic resistance were containing $50 \mathrm{mkg} / \mathrm{ml}$ of compatible antibiotic [13]. There were used the following antibiotics: from $\beta$-lactamic group: Pen/Penicillin, Amp/ampicillin, Amx/Amoxicillin, Amc/Augmentin (the combined preparation of amoxicillin and clavulanic acid (2:1), which is the classical $\beta$-lactamase inhibitor), Cfx/Cefixime and Ctx/ zCeftriaxone; from aminoglycoside group Gen/Gentamicin, Kan/ kanamycin, Str/Streptomycin; from fluoroquinolones group: Cip/Ciprofloxacin; from tetracyclines group: $\mathrm{Tcn} /$ Tetracycline; from azalides of macrolides group:
Azm/azithromycin; from amphenicoles group: Chl/Chloramphenicol. All the used antibiotics were produced by "Astoria". As the positive and the negative control strains there were used the following antibiotic resistant and sensitive bacteria: E. coli DH5 $\alpha$, E. coli

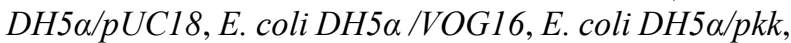
E. coli DH5 $\alpha$ PEC7, as well as P. aeruginosa 9056 and $P$. aeruginosa 5249 strains. The antimicrobial activity tests and the genetical analyses were done according to standard protocols.

The isolation and the purification of plasmid and total DNA was carried out by alkali extraction method and by the method with the use of benzyl chloride and thermic procedure. Then the isolated DNA was researched by $0.8-2.5 \%$ agarose gel electrophoresis. The transformation of sensitive strains by the plasmid DNA, which was isolated resistant strains was realized by Mandel's method of competent cells obtaining with usage of $\mathrm{CaCl}_{2}$ and series of centrifugations in cold temperature. Then for the identification of genes of antibiotic modification were carried out PCR analyses of DNA from the cells of all donors, recipients and transformant strains. The analyses were done with the following primers: $a p h\left(3^{\prime}\right) I V$ (for gene $a p h\left(3^{\prime}\right) I V$ of Aph(3') IV aminoglycoside-3'-phosphotransferase enzyme), $\operatorname{aac}\left(6^{\prime}\right) I I$ (for gene $\operatorname{aac}\left(6^{\prime}\right) I I$ of $\mathrm{Aac}\left(6^{\prime}\right) \mathrm{II}$ aminoglycoside $\quad 6^{\prime}$-N-acetyltransferase enzyme), 
blaOXA-10 (blaOXA-10 gene of $\beta$-lactamase OXA-10 enzyme) and $p C A T 639$ (for gene catB7 of CatB7 Chloramphenicol acetyltransferase enzyme). As the marker it was used the standard mix of DNA fragments EcoRI/Hind III $[13,14]$.

\section{RESULTS}

During the tests of antibiotic resistance using 13 compounds, it was found out that the researched strains are sensitive only to few antibiotics. The results of these experiments are presented on Table-1. According to Table-1 data, the majority of studied strains of microorganisms have demonstrated high level of resistance, including multi-drug and pan-drug resistance. Then all the sensitive and antibiotic resistant strains were studied in scope of their plasmid consistence, for what the DNA was isolated and researched. According to data from Table-1, it is makeable the predominance of plasmid-containing strains in all 3 subtypes of researched $P$. syringae strains group. Anyhow, among the strains which are not containing any plasmids it is detected the resistance to antibiotics.

After the tests of antibiotic-resistance, all the studied strains were tested on media with consistence of tartaric acid newly synthesised cyclic substituent contains derivatives in different concentrations. There were used 3 representatives of tartaric acid imides (benzylimide, cyclohexylimide and phenylimide) and 3 representatives of complex mono amino salts (benzyl mono amino salts, cyclohexyl mono amino salts, phenyl mono amino salts) of tartaric acid. The results of antimicrobial activity tests of tartaric acid 6 semisynthetic derivatives (Fig-2) are presented on Table-2.<smiles>C[C@H]1C(=O)N(c2ccccc2[N+](=O)[O-])C(=O)[C@H]1O[C@H]1CCCCC1N1C(=O)[C@@H](O)[C@@H](O)C1=O</smiles>

Fig-2: Tartaric acid synthetic 6 derivatives: A - benzylimide of tartaric acid (BI), B - cyclohexylimide of tartaric acid (CI), C - phenylimide of tartaric acid (PhI), D - benzyl mono amino salt of tartaric acid (BAS), $\mathrm{E}$ - cyclohexyl mono amino salt of tartaric acid (CAS), F - Phenyl mono amino salt of tartaric acid (PHAS)

A - aminoglycosides (1 - Kan, 2 - Stp, 3 - Gen), $\mathrm{B}$ - amphenicoles $(4-\mathrm{Cam}), \mathrm{C}$ - $\beta$ lactamases (5 - Amc, 6 - Amx, 7 - Amp, 8 - Pcn, 9 - Cfx, 10 - Ctx), D tetracyclines $(11-\mathrm{Tcn}), \mathrm{E}-$ azalides of macrolides $(12-$ Azm), F - fluoroquinolones (13 - Cip), P - plasmid; “+”
- growth/plasmid presence, “_“ - absence of growth/plasmid; CG - the positive control on nutrient agarised cultural media; strains: I - $P$. syringae, II - $P$. syringae, path. lachrymans; III - P. syringae, path. Tabaci.

Table-1: $P$. syringae antibiotic resistance

\begin{tabular}{|c|c|c|c|c|c|c|c|c|c|c|c|c|c|c|c|}
\hline Strain & \multicolumn{3}{|c|}{ A } & B & \multicolumn{5}{|l|}{$\mathrm{C}$} & D & $E$ & $\mathrm{~F}$ & $\mathrm{G}$ & $\mathrm{P}$ & CG \\
\hline I & 1 & 2 & 3 & 4 & 5 & 6 & 7 & 8 & 9 & 10 & 11 & 12 & 13 & & \\
\hline 8744 & - & - & + & - & + & + & + & + & + & + & + & - & + & & + \\
\hline 8740 & + & + & + & + & - & + & + & + & + & + & + & + & + & & + \\
\hline 8756 & - & - & - & - & + & + & + & + & + & + & + & + & - & & + \\
\hline 8656 & + & + & $-*$ & + & + & + & - & + & + & + & + & + & + & & + \\
\hline II & 1 & 2 & 3 & 4 & 5 & 6 & 7 & 8 & 9 & 10 & 11 & 12 & 13 & $\mathbf{P}$ & $\mathrm{C}$ \\
\hline 8730 & - & - & - & - & + & + & + & + & + & + & - & + & + & + & + \\
\hline 8731 & - & - & - & + & + & + & + & - & $-*$ & + & - & - & + & + & + \\
\hline III & 1 & 2 & 3 & 4 & 5 & 6 & 7 & 8 & 9 & 10 & 11 & 12 & 13 & $\mathbf{P}$ & $\mathrm{C}$ \\
\hline 8665 & + & + & + & + & - & + & - & + & + & + & + & + & + & + & + \\
\hline 8657 & + & - & + & - & + & + & + & + & + & + & + & - & - & + & + \\
\hline
\end{tabular}

The strains: (I - P. syringae, II - P. syringae, path. lachrymans; III - P. syringae, path. tabaci), T ability to transformation, $\mathrm{P}$ - plasmid presence, "+" - presence of gene/plasmid, “_“ - absence of gene/plasmid, "c+" - presence on bacterial chromosome, " $p+$ " - presence on plasmid. 
Table-2: The genetic parameters of the research strains of phytopathogens

\begin{tabular}{|l|l|l|l|l|l|l|}
\hline Strain & \multicolumn{2}{|l}{ PCR analysis } & P & T \\
\cline { 1 - 6 } I & $A p h\left(3^{\prime}\right) I V$ & $A a c\left(6^{\prime}\right) I I$ & atB7 & blaOXA-10 & & \\
\hline 8744 & - & - & - & - & - & - \\
\hline 8740 & - & - & - & $C+$ & + & - \\
\hline 8756 & - & - & - & - & - & - \\
\hline 8656 & - & - & - & - & + & + \\
\hline II & $A p h\left(3^{\prime}\right) I V$ & $A a c\left(6^{\prime}\right) I I$ & atB7 & blaOXA-10 & $\mathrm{P}$ & $\mathrm{T}$ \\
\hline 8730 & - & - & - & - & + & + \\
\hline 8731 & - & - & - & - & + & + \\
\hline III & Aph $\left(3^{\prime}\right) I V$ & $A a c\left(6^{\prime}\right) I I$ & atB7 & blaOXA-10 & $\mathrm{P}$ & $\mathrm{T}$ \\
\hline 8665 & - & - & - & - & + & - \\
\hline 8657 & - & - & - & - & + & + \\
\hline
\end{tabular}

The strains (I - P. syringae, II - P. syringae, path. lachrymans; III - P. syringae, path. tabaci) were cultivated on media with $0.5 \mathrm{M}$ and $0,1 \mathrm{M}$ consistence of TA derivatives: BI - benzylimide of TA, CI Cyclohexylimide of tartaric acid, BAS - mono amino salt of benzyl amine of tartaric acid; CAS- mono amino salts of cyclohexyl amine of TA; KT - tartrate of potassium, NK - sodium potassium tartrate, TA - tartaric acid; “+” - growth; L - total lysis of cells; the diameters of cells growth inhibition spots are presented in millimetres, $\mathrm{C}-$ the positive control on nutrient agarised cultural media; strains with zone $30 \mathrm{~mm}$ of growth.

Table-3: TA derivatives activity on Pseudomonas syringae

\begin{tabular}{|l|l|l|l|l|l|l|l|l|l|l|l|l|l|l|l|l|l|l|l|}
\hline Strain & \multicolumn{3}{l}{ BAS } & \multicolumn{3}{l}{ BI } & \multicolumn{2}{l}{ CAS } & \multicolumn{2}{l}{ CI } & \multicolumn{2}{l}{ PhAS } & \multicolumn{2}{l}{ PhI } & KT & NK & TA & C \\
\hline I & $\mathbf{0 . 5}$ & $\mathbf{0 . 1}$ & $\mathbf{0 . 5}$ & $\mathbf{0 . 1}$ & $\mathbf{0 . 5}$ & $\mathbf{0 . 1}$ & $\mathbf{0 . 5}$ & $\mathbf{0 . 1}$ & $\mathbf{0 . 5}$ & $\mathbf{0 . 1}$ & $\mathbf{0 . 5}$ & $\mathbf{0 . 1}$ & $\mathbf{0 . 5}$ & $\mathbf{0 . 5}$ & $\mathbf{0 . 5}$ & \\
\hline 8744 & L & L & 18 & 16 & 14 & 7 & L & 5.2 & 3 & 2.4 & 5 & 3.1 & + & + & 10 & + \\
\hline 8740 & 15 & 1.2 & 18 & 17 & 7 & + & 15 & 8.9 & 4 & 3.2 & + & 2.7 & + & + & 8.2 & + \\
\hline 8756 & 10 & 9.1 & L & L & 15 & + & L & 15 & 2 & 1.5 & + & + & + & + & 10 & + \\
\hline 8656 & 12 & 12 & L & L & 15 & 10 & L & 15 & 1.7 & 1 & + & + & 5 & + & 10 & + \\
\hline II & $\mathbf{0 . 5}$ & $\mathbf{0 . 1}$ & $\mathbf{0 . 5}$ & $\mathbf{0 . 1}$ & $\mathbf{0 . 5}$ & $\mathbf{0 . 1}$ & $\mathbf{0 . 5}$ & $\mathbf{0 . 1}$ & $\mathbf{0 . 5}$ & $\mathbf{0 . 1}$ & $\mathbf{0 . 5}$ & $\mathbf{0 . 1}$ & $\mathbf{0 . 5}$ & $\mathbf{0 . 5}$ & $\mathbf{0 . 5}$ & C \\
\hline 8730 & 8 & 6 & 4 & 3 & L & L & 28 & 21 & 8 & 3.2 & 15 & 13 & + & + & 2.5 & + \\
\hline 8731 & 3 & 1.2 & L & L & L & L & 26 & 25 & 17 & 14 & 6.1 & 3.2 & + & + & 3 & + \\
\hline III & $\mathbf{0 . 5}$ & $\mathbf{0 . 1}$ & $\mathbf{0 . 5}$ & $\mathbf{0 . 1}$ & $\mathbf{0 . 5}$ & $\mathbf{0 . 1}$ & $\mathbf{0 . 5}$ & $\mathbf{0 . 1}$ & $\mathbf{0 . 5}$ & $\mathbf{0 . 1}$ & $\mathbf{0 . 5}$ & $\mathbf{0 . 1}$ & $\mathbf{0 . 5}$ & $\mathbf{0 . 5}$ & $\mathbf{0 . 5}$ & C \\
\hline 8665 & 4.5 & 4 & 8.1 & 7 & L & 10 & 27 & 24 & 6.5 & 5 & 5.5 & 4.8 & 1.5 & 1.5 & 3 & + \\
\hline 8657 & 7.3 & 5 & 6 & 4 & 15 & 11 & 20 & 17 & L & 15 & 7.4 & 6.7 & 1.5 & 1.3 & 4 & + \\
\hline
\end{tabular}

\section{DISCUSSION}

During all the experiments with $P$. syringae 3 pathovars it was found out that all the tested compounds are effective in concentrations $0,05 \mathrm{M}$ to $0,01 \mathrm{M}$, depends to different strains, among which there were indicated as non-plasmid strains as well as plasmid-containing strains. For this researched group of strains of it was defined as $0,05 \mathrm{M}$ with inhibition zones diameter up to $20 \mathrm{~mm}$. As it was shown on Table-2, the synthetic derivatives are more effective than the tartaric acid and the natural salts of it. Only for small quantity of researched strains benzyl mono amino salt is not effective. Imides are more effective and led to lytic effect. According to various research, these types of compounds are degradable chemically, upon the influence of acidic and alkali $\mathrm{pH}$ reaction of soil. Besides, some cyclic imides are biodegradable too [15, 16]. That is why probably, cyclohexyl- benzyl- and phenyl- imide derivatives can be considered as non-stabile pollutant of soil, what makes them describable as potentially ecologically safe compounds. According to previous research on other representatives of Pseudomonas, these compounds showed the high efficiency but they are les degradable by soil bacteria then mono amino salts. The usage of tartaric acid derivatives has a range of advantages in comparison with other methods. Due to the previous research, it was detected the absence or resistance spread by plasmids from strains of $P$. aeruginosa, $P$. fluorescens, $P$. putida and $S$. maltophilia which were non sensitive to tartaric acid benzylimide and cyclohexylimide as well as benzyl and cyclohexyl complex salts to different representatives of Pseudomonas, Stenotrophomonas, E. coli and other species of Gram-negative microorganisms [17].

It is also known that tartaric acid and its derivatives do not inhibit the viability of the probiotic strains of Bifidobacterium and Lactobacillus in gastrointestinal tracts. For some examples of amino derivatives: mono-/di-amides, as well as polyamides, it was defined that they exhibit the high bactericidal activity against the various of pathogenic microorganisms, such as like: Salmonella typhae, Bacillus subtilis, E. coli, P. aeruginosa, Shigella sp., 
Bacillus cereus and fungicidal activity against Trichophytum rubrum [18]. Thus, available natural tartaric acid, tartrates of metals and other derivatives of it, might become the one of the best alternative solutions for multi-drug resistant pathogen combating in case of agricultural pests and pathogens.

\section{CONCLUSION}

During all the experiments with tartaric acid synthetic derivatives in 2 forms (imides and complex salts) on different native soil strains of phytopathogenic Pseudomonas syringae, the antimicrobial effect of researched 6 compounds was detected. Benzylimide, Cyclohexylimide, as well as benzyl and cyclohexyl mono amino salts had demonstrated themselves as highly effective antibacterial compounds against the antibiotic resistant strains isolated from soil. Phenylderivatives are more effective only for part of strains. Antimicrobial activity of newly synthesized compounds in a majority of cases was stronger than in case tartaric acid and the well-known derivatives usage. For all the studied microbes during the one week of cultivation the secondary growth after the influence of 6 representatives of tested 2 new classes of tartaric acid derivatives was not detected. Cyclohexyl- substituent containing derivatives of tartaric acid, are more effective, then benzyl- substituted derivatives. Thus, all the tested semisynthetic compounds which are based on natural L-tartaric acid, are recommended for various further research of their efficiency as prospective antibacterial agents and their ecological safeness, being a potentially biodegradative compounds.

\section{ACKNOWLEDGMENT}

This research was supported by The Ministry of Education, Science, Culture and Sports, RA, SCS grant research projects № 15Ap_2e016, № 18T-2I036 and research grant from ANSEF, New York, USA, grant \#microbio-5133.

\section{REFERENCES}

1. Cholet C, Claverol S, Claisse O, Rabot A, Osowsky A, Dumot V, Ferrari G, Gény L. Tartaric acid pathways in Vitis vinifera L.(cv. Ugni blanc): a comparative study of two vintages with contrasted climatic conditions. BMC plant biology. 2016 Dec 1;16(1):144.

2. DeBolt S, Cook DR, Ford CM. L-Tartaric acid synthesis from vitamin $\mathrm{C}$ in higher plants. Proceedings of the National Academy of Sciences. 2006 Apr 4;103(14):5608-13.

3. Maroun RG, Rajha HN, Vorobiev E, Louka N. Emerging technologies for the recovery of valuable compounds from grape processing by-products. InHandbook of Grape Processing By-Products 2017 Jan 1 (pp. 155-181). Academic Press.

4. Khan SW, Naz S, Zaidi JH, Ambreen N, Khan KM, Perveen S, Miana GA. Synthesis and antimicrobial activity of chiral imides from diacetyl-1-tartaric acid anhydride and different amino acids. J. Pharm. Res. 2012 Jan;5:646-50.

5. Malik M, Khan SW, Arfan M, Zaidi JH, Bano A, Ullah F. Biological Evaluation of Chiral Amides Synthesized from Diacetyl-L-tartaric Acid and Aromatic Amines. Asian Journal of Chemistry. 2013 Jan 21;25(2):745.

6. El Chakhtoura NG, Saade E, Iovleva A, Yasmin M, Wilson B, Perez F, Bonomo RA. Therapies for multidrug resistant and extensively drug-resistant non-fermenting gram-negative bacteria causing nosocomial infections: a perilous journey toward 'molecularly targeted'therapy. Expert review of anti-infective therapy. 2018 Feb 1;16(2):89-110.

7. Adesoji AT, Ogunjobi AA, Olatoye IO. Molecular characterization of selected multidrug resistant Pseudomonas from water distribution systems in southwestern Nigeria. Annals of clinical microbiology and antimicrobials. 2015 Dec;14(1):39.

8. Martin GB. Suppression and activation of the plant immune system by Pseudomonas syringae effectors AvrPto and AvrPtoB. Effectors in plant-microbe interactions. 2012 Jan 3;84(2):123-54.

9. Sundin GW, Wang N. Antibiotic resistance in plant-pathogenic bacteria. Annual review of phytopathology. 2018 Aug 25;56:161-80.

10. de Araujo GG, Rodrigues F, Gonçalves FL, Galante D. Survival and ice nucleation activity of Pseudomonas syringae strains exposed to simulated high-altitude atmospheric conditions. Scientific reports. 2019 May 23;9(1):1-11.

11. Dashchyan NA, Asatryan NL, Galstyan GF, Mikaelyan AR. Obtaining bioactive additives of cyclic structure on the basis of optically active tartaric acid. Bulletin of NPUA, Collection of scientific papers, part II. 2014:682-683.

12. Appelman B, Erickson AI, Lu LL, Weltman RE, inventors; Facebook Inc, assignee. Dynamic location of a subordinate user. United States patent application US 13/620,865. 2013 Mar 21.

13. Babayan BG, Hovhannisyan NA, Hovhannisyan AM, Sargsyan AS, Davidyan TS. Resistance To $\beta$-Lactam Antibiotics In Some Soil Stenotrophomonas and Pseudomonas, Hungary: The Scientific-Heritage, 2019;5(2):32-38.

14. Chaudhary DK, Khulan A, Kim J. Development of a novel cultivation technique for uncultured soil bacteria. Scientific reports. 2019 Apr 30;9(1):1-11.

15. Zhu J, Zhao Y, Ruan H. Comparative study on the biodegradation of chlorpyrifos-methyl by Bacillus megaterium CM-Z19 and Pseudomonas syringae CM-Z6. Anais da Academia Brasileira de Ciências. 2019;91(3):e20180694.

16. Martin C, Davet P, Véga D, Coste C. Field effectiveness and biodegradation of cyclic imides in lettuce field soils. Pesticide science. 1991;32(4):427-38. 
Bella G. Babayan et al., Sch Acad J Biosci, May, 2020; 8(5): 127-132

17. Mikaelyan AR, Asatryan NL, Bagdasaryan SA, Babayan BG. Antimicrobial Activity of Newly Synthesized Derivatives of Tartaric Acid Against the Multidrug Resistant Soil Strains of Pseudomonas and Stenotrophomonas, ARICBE/ARICPAS-2019 Cambridge University, Abstract Book, Cambridge, UK, 2019; 23.
18. Kenawy ER, Abdel- Hay FI, Shahada L, ElShanshoury AE, El- Newehy MH. Biologically active polymers. IV. Synthesis and antimicrobial activity of tartaric acid polyamides. Journal of applied polymer science. 2006 Dec 5;102(5):4780-90. 